\title{
What is Normal Profit for power generation?
}

\author{
Paul Simshauser and Jude Ariyaratnam* \\ Level 6, 144 Edward Street \\ Brisbane, QLD 4001 \\ June 2013
}

\begin{abstract}
One of the seemingly complex areas associated with energy-only wholesale electricity pools is at what point the abuse of market power is present on the supply-side. It shouldn't be this way. If a theoretically robust measure of Normal Profit exists, identification of potential market power abuse is straight-forward. Such a definition readily exists and can be traced back to the ground-breaking work of financial economists in the 1960s. In this article, we present a multi-period dynamic power project financing model to produce pragmatic estimates of benchmark wholesale power prices based on the principles of Normal Profit. This in turn can guide policymakers as to whether price spikes or bidding above marginal cost in wholesale electricity markets warrants any investigation at all.
\end{abstract}

Keywords: Profit, Project Finance, Electricity Prices.

JEL Codes: D61, L94, L11 and Q40.

\section{Introduction}

Transient price spikes in gross pool, energy-only, uniform first-price auction wholesale markets typically trigger regulatory inquiry. Policy intervention may be warranted if supranormal profits are being extracted on a sustained basis through generator bidding behaviour in the presence of demonstrable barriers to entry. But episodes of transient price spikes in energy-only markets should not represent an 'automatic' trigger for inquiry let alone policy intervention, particularly if underlying prices are otherwise driving merchant generators to a state of financial distress.

Economic theory has long demonstrated that energy-only spot electricity markets can clear demand reliably, and can provide suitable investment signals for new capacity (Schweppe et al. 1988). But such analysis typically presumes unlimited market price caps, limited political or regulatory interference, and by deduction, a largely equity capital-funded generation fleet able to withstand wildly fluctuating business cycles. Unfortunately the real world isn't this convenient.

Rarely are generators devoid of scheduled debt repayments and so theories of spot energy markets suffer from the inadequate treatment of how non-trivial sunk capital costs are financed (Peluchon, 2003; Joskow, 2006; Finon, 2008; Caplan, 2012; Nelson and Simshauser, 2013). Additionally, wholesale price caps do exist and are enforced - in some instances excessively so by regulatory authorities (Besser et al. 2002; Oren, 2003; de Vries, 2003; Wen et al. 2004; Finon and Pignon, 2008, Joskow 2008a, Simshauser, 2010). Intensely competitive energy-only markets are known to produce inadequate net revenues to support investment in the optimal least cost generating portfolio, otherwise known as the 'missing money' problem (Neuhoff et al. 2004; de Vries, 2004; de Vries et al. 2008; Bushnell, 2005; Roques et al. 2005; Cramton and Stoft, 2006; Joskow, 2008b; Finon, 2008; Simshauser, 2008). In short, given substantial fixed and sunk costs associated with power generation, and low marginal production costs, persistent generator bidding at short run marginal cost does not result in a stable equilibrium (Bidwell and Henney,

\footnotetext{
- Paul Simshauser is the Chief Economist at AGL Energy Ltd and Professor of Economics at Griffith University. Jude Ariyaratnam is a financial analyst at AGL Energy Ltd. The authors are grateful to Rob Prest (Macquarie Capital), James Nelson (PwC) and AGL Energy Ltd's Applied Economic and Policy Research Council for reviewing earlier drafts. However, as noted in Appendix IV, any errors or omissions remain entirely the responsibility of the authors.
} 
2004; Simshauser, 2008; Nelson and Simshauser, 2013). Generator bidding must, therefore, deviate from strict marginal cost at some point. But given an oligopolistic market environment, at what point might this cross a line and represent a potential abuse of market power that warrants investigation and possible intervention by policymakers? If a pragmatic measure of Normal Profit exists, then contrasting Normal Profit with a combination of actual (historic) base load spot prices and futures prices for call option contracts can provide suitable guidance.

Identifying a theoretically sound measure of Normal Profit is of vital importance to the industry, policymakers, and in turn, the overall efficiency and welfare of the macro economy. The allocation of resources within an economy relies quite fundamentally on such constructs, whether this is through the investment decisions of firms, or by decisions made by policymakers that influence or directly impact on investment outcomes. But Normal Profit needs to be very carefully defined.

The concept of Normal Profit is unremarkable in economics but oddly enough is very rarely identified in practice. This is primarily because profit announcements by firms (and reported by the media) are dominated by accounting statistics and ratios based on the traditional measure of Net Profit after Tax (NPAT). Finance theory is clear - NPAT is nothing more than a residual measure. When NPAT is determined by traditional accounting axioms, it represents the residual funds available for distribution to stockholders after all other claimants have been satisfied. NPAT does not describe the 'pitch' of profits generated, that is, Normal or otherwise.

In order to assess the pitch of profits, a suitable benchmark must first be defined. Economic theory has long told us that this is measured by the opportunity cost of funds employed. By the 1960s, the economics profession had produced profoundly more refined quantitative definitions, viz. the marginal cost of capital or expected returns of rational investors based on a one factor, two-parameter model of risk and return. The origins of the Capital Asset Pricing Model can be traced back to Sharpe (1964) and Lintner (1965). If profits of the firm meet the marginal cost of capital, a Normal Profit has been generated. Supranormal profits are achieved when profit exceeds the cost of capital and conversely, economic losses occur when returns fail to meet expected returns.

In our experience, a surprising number of policymakers, regulators and microeconomics professionals (from academia and industry) misinterpret the appropriate quantitative value for the marginal cost of capital. The reason for this, we suspect, is that the theoretical construct of 'opportunity cost' must shift from theory to practice, all the while ensuring that in the process the result does not violate the basic axioms and constraints of credit metrics and taxation implications - all of which are important in defining the true marginal efficiency of equity and debt capital. The shift from theory to practice is thus grounded in financial economics, not microeconomics.

For highly capital-intensive industries like power generation, temporal issues associated with accounting results create further complications. Accounting numbers use arbitrary reporting periods (e.g. monthly, quarterly, annual) to measure NPAT. While this is both desirable and necessary for managerial and agency purposes, discrete accounting period reporting is fundamentally a static analysis, whereas for investment or policymaking purposes, Normal Profit should be considered in a dynamic context. The expected returns of capital-intensive assets occur over multiple decades and in power generation are subject to (nominally) 5-7 year business cycles, with actual returns oscillating considerably around the mean outcome. Normal Profit, then, must be considered as a multi-period dynamic inquiry rather than a static analysis based on a collection of half-hour price spikes during a short episode of hot weather, for example.

In economics literature, from a benchmark perspective the Internal Rate of Return (IRR) of investments is the most prominently used theoretical long-run profitability concept as Salmi and 
Virtanen (1997) explain. Finance literature on the other hand has a distinct bias towards net present value analysis, although as Brealey, Myers and Allen (2011) observe, IRR comes from respectable ancestry, and for our purposes, can be expected to provide conforming results under all of the conditions that we envisage in this article. ${ }^{1}$

From a competition perspective using a Normal Profit benchmark, analysed over a business cycle, provides a suitable threshold for regulatory authorities to consider. Normal Profit is also of central importance in broader policymaking - if benchmarks are over-estimated consumer welfare can be adversely affected and resource allocation to other industries may be scaled-back to inefficient levels. Conversely, underestimation of Normal Profit can lead to policy settings that benefit consumers in the short run but the associated wealth transfers adversely affect industry investment, competition and innovation in the long run, and will eventually harm consumers. Neither outcome is desirable.

The purpose of this article is to set out a theoretically robust and pragmatic approach which defines 'Normal Profit' in power generation which is then transposed into base electricity prices and call option prices. This requires that we define the cost of debt and the cost of equity capital for the two most prominent business combinations in merchant energy markets, and to set out a clear quantitative methodology for quantifying the long run marginal cost of power generation given prevailing capital and factor market conditions. While our application to power generation uses Australian data, the framework is equally applicable to other regions with energy-only market models such as those in Australia, Texas, New Zealand, Singapore, Alberta (Canada) and Europe amongst others.

This article is structured as follows. Section 2 outlines our dynamic power project financial model which produces generalised long run marginal cost estimates for multiple technologies. Section 3 outlines our input assumptions and presents our model results while Section 4 applies the results to policymaking. Concluding remarks follow.

\section{Generalised long run marginal cost of generation plant - PF Model}

The model we use to produce a theoretically sound profit benchmark and generalised long run marginal cost estimates for generating plant is a dynamic, multi-period model with all outputs expressed in nominal dollars and post-tax discounted cash flows focusing on and solving for multiple generating technologies, business combinations and revenue possibilities, and simultaneously solves for convergent price, debt-sizing, and equity returns $K_{e}$.

To begin with, since all outputs are expressed in nominal dollars, costs are increased annually by a forecast general inflation rate estimate (CPI) with prices escalating at a discount to our assumed CPI. Inflation rates for revenue streams $\pi_{j}^{R}$ and cost streams $\pi_{j}^{C}$ in period (year) $j$ are calculated in the model as follows:

$\pi_{j}^{R}=\left[1+\left(\frac{C P I \times \alpha_{R}}{100}\right)\right]^{j}$, and $\pi_{j}^{C}=\left[1+\left(\frac{C P I \times \alpha_{C}}{100}\right)\right]^{j}$

In this instance, $\alpha_{C}$ is the adjustment factor of 1.0 for costs and $\alpha_{R}$ relates to revenues and is set at 0.75 . The discounted value for $\alpha_{R}$ is intended to reflect single factor learning rates that characterise generating technologies over time. ${ }^{2}$

\subsection{PF Model for base, semi-base and intermittent power plant}

Energy output from each power plant (i) is a key variable in driving revenue streams, unit fuel costs and variable Operations \& Maintenance costs. Energy output is calculated by reference to installed capacity $k^{i}$, capacity utilisation rate $C F_{j}^{i}$ and run time $t$, which in the PF Model is 
8760hrs for each period $j$. Auxillary losses $A u x^{i}$ arising from on-site electrical loads (such as air compressors, lighting, induced and forced draft fans and so on) need to be deducted.

$\rho_{j}^{i}=C F_{j}^{i} \cdot t \cdot k^{i} .\left(1-A u x^{i}\right)$

There are two options for convergent electricity prices in the PF Model. The first option is to exogenously set unique forecast prices for each period $j$ (e.g. from a dynamic partial equilibrium model of the relevant power system), while the second option, which is our default option and used throughout this article is a calculated price in year one which escalates electricity price $P^{\varepsilon}$ at the rate of $\pi_{j}^{R}$ from equation (4). Additionally, ancillary services revenues have been set at $0.25 \%$ of electricity sales. ${ }^{3}$ Thus revenue in each period $j$ is defined as follows:

$R_{j}^{E}=\left(\rho_{j}^{i} \cdot P^{\varepsilon} \cdot \pi_{j}^{R}\right) \times 1.0025$

To determine the short run marginal cost of the $i^{\text {th }}$ plant in the $j^{\text {th }}$ period, the thermal efficiency for each generation technology $\zeta^{i}$ needs to be defined. The constant term ' 3600 ' 4 is divided by the thermal efficiency variable to convert the result from per cent to $\mathrm{kJ} / \mathrm{kWh}$, which is then multiplied by the commodity cost of raw fuel $F^{i}$. Variable Operations \& Maintenance costs $v^{i}$ is also added to provide a pre-carbon short run marginal cost. To the extent that the plant has non-zero $\mathrm{CO}_{2}$ emissions and faces an emissions trading regime, the $\mathrm{CO}_{2}$ intensity of output for the $i^{\text {th }}$ plant needs to be computed along with the relevant $\mathrm{CO}_{2}$ price, $C P_{j}$. In order to define a value for plant carbon intensity $g^{i}$, the relevant combustion emissions factor $\dot{g}^{i}$ and fugitive $\mathrm{CO}_{2}$ emissions from the fuel source $\hat{g}^{i}$ are multiplied by the plant heat rate. Marginal running costs in the $j^{\text {th }}$ period is then calculated by the product of short run marginal production costs by generation output $\rho_{j}^{i}$ and escalated at the rate of $\pi_{j}^{C}$.

$\vartheta_{j}^{i}=\left\{\left[\left(\frac{\left(3600 / \zeta^{i}\right)}{1000} \cdot F^{i}+v^{i}\right)+\left(g^{i} \cdot C P_{j}\right)\right] \cdot \rho_{j}^{i} \cdot \pi_{j}^{C} \mid g^{i}=\left(\dot{g}^{i}+\hat{g}^{i}\right) \cdot \frac{\left(3600 / \zeta^{i}\right)}{1000}\right\}$

Fixed Operations \& Maintenance costs $f_{j}^{i}$ of the plant are measured in \$/MW/year of installed capacity $F C^{i}$ and are multiplied by plant capacity $k^{i}$ and escalated.

$f_{j}^{i}=F C^{i} \cdot k^{i} \cdot \pi_{j}^{C}$

Earnings Before Interest Tax Depreciation and Amortisation (EBITDA), a frequently used accounting-based measure, in the $j^{\text {th }}$ period can be defined as follows:

$E B I T D A_{j}^{i}=\left(R_{j}^{E}-\vartheta_{j}^{i}-f_{j}^{i}\right)$

Unless plant is acquired, capital costs associated with development involve a multi-period construction program. Capital costs are therefore defined as follows:

$X_{j}^{i}=-\sum_{k=1}^{N} C_{k} \cdot\left(1+K_{e}\right)^{-k}$

Ongoing capital spending for each period $j$ is determined as the inflated annual assumed capital works program.

$x_{j}^{i}=c_{j}^{i} \cdot \pi_{j}^{C}$ 
Plant capital costs $X_{j}^{i}$ give rise to tax depreciation $\left(d_{j}^{i}\right)$ such that if the current period was greater than the plant life under taxation law $(L)$, then the value is 0 . In addition, $x_{j}^{i}$ also gives rise to tax depreciation such that:

$d_{j}^{i}=\left(\frac{x_{j}^{i}}{L}\right)+\left(\frac{x_{j}^{i}}{L+1-j}\right)$

From here, taxation payable $\left(\tau_{j}^{i}\right)$ at the corporate taxation rate $\left(\tau_{c}\right)$ is applied to EBITD $A_{j}^{i}$ less Interest on Loans defined later in (16), less $d_{j}^{i}$. To the extent $\left(\tau_{j}^{i}\right)$ results in non-positive outcome, tax losses $\left(L_{j}^{i}\right)$ are carried forward and offset against future periods.

$\operatorname{Max}\left(\tau_{j}^{i}, 0\right)=\left(E B I T D A_{j}^{i}-I_{j}^{i}-d_{j}^{i}-L_{j-1}^{i}\right) \cdot \tau_{c}$

Our debt financing model computes the interest and principal repayments on different debt facilities depending on the type and tenor of each tranche. For example, we model project financings with two facilities; (1) nominally a 5-year bullet, requiring interest-only payments after which it is refinanced with two consecutive 10-year amortising facilities. The first refinancing is set in a semi-permanent structure with a nominal repayment term of 20 years, while the second is fully amortised over the 10 year tenor. The second facility (2) commences with a tenor of 12 years as an amortising facility, again set within a semi-permanent structure with a nominal repayment term of 27 years. This second tranche is refinanced in year 13 and extinguished over a further 15 year period. Consequently, all debt is extinguished by year 27. The decision tree for the two tranches of debt was the same, so for the Debt Tranche where $T=1$ or 2 , the calculation is as follows:

if $j\left\{\begin{array}{l}>1, D T_{j}^{i}=D T_{j-1}^{i}-P_{j-1}^{i} \\ =1, D T=D_{0}^{i} . S\end{array}\right.$

$D_{0}^{i}$ refers to the total amount of debt used in the project. The split $(S)$ of the debt between each facility refers to the manner in which the debt is apportioned to each debt tranche. We assume $35 \%$ of the debt was assigned to Tranche 1 and the remainder to Tranche 2 in a manner consistent with Simshauser (2009). Principal $P_{j-1}^{i}$ refers to the amount of principal repayment for tranche $T$ in period $j$ and is calculated as an annuity:

$P_{j}^{i}=\left(\frac{D T_{j}^{i}}{\left[\frac{1-\left(1+\left(R_{T}^{Z}+C_{T}^{Z}\right)\right)^{-n}}{R_{T}^{Z}+C_{T}^{Z}}\right]} \mid Z\left\{\begin{array}{c}=V I \\ =P F\end{array}\right)\right.$

In (15), $R_{T}$ is the fixed (reference) interest rate and $C_{T}$ is the credit spread or margin relevant to the issued Debt Tranche. The relevant interest payment in the $j^{\text {th }}$ period $\left(I_{j}^{i}\right)$ is calculated as the product of the (fixed) interest rate on the loan by the amount of loan outstanding:

$I_{j}^{i}=D T_{j}^{i} \times\left(R_{T}^{Z}+C_{T}^{Z}\right)$

Total Debt outstanding $D_{j}^{i}$, total Interest $I_{j}^{i}$ and total Principle $P_{j}^{i}$ for the $i^{\text {th }}$ plant is calculated as the sum of the above components for the two debt tranches in time $j$. For clarity, Loan Drawings are equal to $D_{0}^{i}$ in year 1 as part of the initial financing and are otherwise 0 .

In equation (14) one of the key calculations is the initial derivation of $D_{0}^{i}$. This is determined by the product of the gearing level and the acquisition/development cost. The gearing level in turn is 
formed by applying a cash flow constraint based on credit metrics applied by capital markets. In this instance, the variable $\varphi$ in our PF Model relates specifically to the business combination and the credible capital structure achievable. The two relevant combinations are Vertically Integrated (VI) merchant utilities and stand-alone Project Financed Merchant (PF) businesses.

if $\varphi\left\{\begin{array}{l}\quad=V I, \operatorname{Min}\left(\frac{F F O_{j}^{i}}{I_{j}^{i}}\right) \geq \delta_{j}^{V I \wedge} \operatorname{Min}\left(\frac{F F O_{j}^{i}}{D_{j}^{i}}\right) \geq \omega_{j}^{V I} \forall j \mid F F O_{j}^{i}=\left(E B I T D A_{j}^{i}-x_{j}^{i}\right) \\ =P F, \operatorname{Min}\left(D S C R_{j}^{i}, L L C R_{j}^{i}\right) \geq \delta_{j}^{P F}, \forall j \mid D S C R_{j}=\frac{\left(E B I T D A_{j}^{i}-x_{j}^{i}-\tau_{j}^{i}\right)}{P_{j}^{i}+I_{j}^{i}}, L L C R_{j}=\frac{\sum_{j=1}^{N}\left[\left(E B I T D A_{j}^{i}-x_{j}^{i}-\tau_{j}^{i}\right) \cdot\left(1+K_{d}\right)^{j}\right]}{D_{j}^{i}}\end{array}\right.$

The variables $\delta_{j}^{V I}$ and $\omega_{j}^{V I}$ are exogenously determined by credit rating agencies. Values for $\delta_{j}^{P F}$ are exogenously determined by project banks and depend on technology (i.e. thermal vs. renewable) and the extent of energy market exposure, that is whether a Power Purchase Agreement exists or not. For clarity, $F F O_{j}^{i}$ is 'Funds From Operations' while $D S C R_{j}^{i}$ and $L L C R_{j}^{i}$ are the Debt Service Cover Ratio and Loan Life Cover Ratios.

At this point, all of the necessary conditions exist to produce estimates of the long run marginal cost of power generation technologies, and a suitable benchmark for what constitutes Normal Profit. As noted at the outset of this article, in economics literature IRR is the widely used theoretical long-run profitability concept. The relevant equation to solve for the price $P^{\varepsilon}$ which produces a normal profit given $K_{e}$ whilst simultaneously meeting the binding constraints of $\delta_{j}^{V I}$ and $\omega_{j}^{V I}$ or $\delta_{j}^{P F}$ given the relevant business combination is as follows:

$-X_{j}^{i}+\sum_{j=1}^{N}\left[E B I T D A_{j}^{i}-I_{j}^{i}-P_{j}^{i}-\tau_{j}^{i}\right] \cdot\left(1+K_{e}\right)^{-(j)}-\sum_{j=1}^{N} x_{j}^{i} \cdot\left(1+K_{e}\right)^{-(j)}-D_{0}^{i}$

The primary objective is to expand every term which contains $P^{\varepsilon}$. Expansion of the EBITDA, Interest and Tax terms is as follows:

$-X_{j}^{i}+\sum_{j=1}^{N}\left[\left(P^{\varepsilon} \cdot \rho_{j}^{i} \cdot \pi_{j}^{R}\right)-\vartheta_{j}^{i}-f_{j}^{i}-D T_{j}^{i} \cdot\left(R_{T}^{Z}+C_{T}^{Z}\right)-P_{j}^{i}-\left(\left(P^{\varepsilon} \cdot \rho_{j}^{i} \cdot \pi_{j}^{R}\right)-\vartheta_{j}^{i}-f_{j}^{i}-I_{j}^{i}-d_{j}^{i}-L_{j-1}^{i}\right) \cdot \tau_{c}\right] \cdot(1+$ $\left.K_{e}\right)^{-(j)}-\sum_{j=1}^{N} x_{j}^{i} \cdot\left(1+K_{e}\right)^{-(j)}-D_{0}^{i}$

We then rearrange the terms such that only the $P^{\varepsilon}$ term is on the left hand side of the equation:

Let $I R R \equiv K_{e}$.

$\sum_{j=1}^{N}\left(1-\tau_{c}\right) \cdot P^{\varepsilon} \cdot \rho_{j}^{i} \cdot \pi_{j}^{R} \cdot\left(1+K_{e}\right)^{-(j)}=X_{j}^{i}-\sum_{j=1}^{N}\left[-\left(1-\tau_{c}\right) \cdot \vartheta_{j}^{i}-\left(1-\tau_{c}\right) \cdot f_{j}^{i}-\left(1-\tau_{c}\right) \cdot\left(D T_{j}^{i} \cdot\left(R_{T}^{Z}+C_{T}^{Z}\right)\right)-\right.$

$\left.\left.P_{j}^{i}+\tau_{c} \cdot d_{j}^{i}+\tau_{c} L_{j-1}^{i}\right) \cdot\left(1+K_{e}\right)^{-(j)}\right]+\sum_{j=1}^{N} x_{j}^{i} \cdot\left(1+K_{e}\right)^{-(j)}+D_{0}^{i}$

We then solve for $P^{\varepsilon}$ such that:

$P^{\varepsilon}=$
$\frac{x_{j}^{i}}{\sum_{j=1}^{N}\left(1-\tau_{c}\right) \cdot P^{\varepsilon} \cdot \rho_{j}^{i} \cdot \pi_{j}^{R} \cdot\left(1+K_{e}\right)^{-(j)}}+\frac{\left.\sum_{j=1}^{N}\left(\left(1-\tau_{c}\right) \cdot \vartheta_{j}^{i}+\left(1-\tau_{c}\right) \cdot f_{j}^{i}+\left(1-\tau_{c}\right) \cdot\left(D T_{j} \cdot\left(R_{T}^{Z}+C_{T}^{Z}\right)\right)+P_{j}^{i}-\tau_{c} \cdot d_{j}^{i}-\tau_{c} L_{j-1}^{i}\right) \cdot\left(1+K_{e}\right)^{-(j)}\right)}{\sum_{j=1}^{N}\left(1-\tau_{c}\right) \cdot P^{\varepsilon} \cdot \rho_{j}^{i} \cdot \pi_{j}^{R} \cdot\left(1+K_{e}\right)^{-(j)}}+$
$\frac{\sum_{j=1}^{N} x_{j}^{i} \cdot\left(1+K_{e}\right)^{(j)}+D_{0}^{i}}{\sum_{j=1}^{N}\left(1-\tau_{c}\right) \cdot P^{\varepsilon} \cdot \rho_{j}^{i} \cdot \pi_{j}^{R} \cdot\left(1+K_{e}\right)^{-(j)}}$

\subsection{PF Model for peaking power plant}

Certain adjustments to the PF Model are required to accommodate long run marginal cost estimates for peaking plant. For base, semi-base and intermittent plant, the normal estimation procedure is to identify the relevant convergent electricity price $P^{\varepsilon}$ that is sufficient to produce an IRR equal to $K_{e}$. The value for $P^{\varepsilon}$ is found by solving equation (21), and one of the most 
sensitive variables is energy output $\rho_{j}^{i}$, which is in turn driven by the value for $C F_{j}^{i}$. In general, values for $C F_{j}^{i}$ are comparatively predictable in that base load plant have high capacity factors and intermittent plant, over time, exhibit output factors within a comparatively tight range given long-run average weather conditions. Peaking plant on the other hand exhibits fluctuating values for $C F_{j}^{i}$ due to the natural volatility inherent in short-run weather patterns and temporal shocks to the demand-supply balance.

This has two primary implications. First, defining a single electricity price $P^{\varepsilon}$ for peaking plant is virtually meaningless in the absence of an expected fixed or 'sticky' $\overline{C F_{J}^{\imath}}$. Second, attempting to define a value for $P^{\varepsilon}$ is likely to render such a project unbankable due to the uncertainty over values for $C F_{j}^{i}$ in application (i.e. by project bank credit committees). Consequently, peaking plant requires a distinct revenue model in its own right. In our opinion, the appropriate way to express generalised long run marginal cost estimates for peaking plant is to define the 'carrying cost' of plant capacity, $\bar{F}_{0}$. This requires only small modifications to the calculation of revenues in our PF Model. The result produced is a single capacity price $P^{k}$ which essentially reflects the equilibrium price of a sold call-option contract at the commonly traded strike price for such instruments of \$300/MWh in Australia’s National Electricity Market. Equations (5) and (6) require reconfiguring as follows:

$\rho_{j}^{i}=0 \forall j$, and $R_{j}^{k}=\left(k^{i} \cdot P^{k} \cdot t \cdot \pi_{j}^{R}\right)$

Here, the value of energy output $\rho_{j}^{i}$ is set to zero, which means marginal running costs $\vartheta_{j}^{i}$ will also be zero. In practice $\rho_{j}^{i}$ will have a non-zero value and so $P^{\varepsilon}$ would also be non-zero, and under most conditions will exceed marginal running costs $\vartheta_{j}^{i}$. This differential between $P^{\varepsilon}$ and $\vartheta_{j}^{i}$, while somewhat contentious to model, will be limited in each sub-period of $j$ by the call option strike price, and for our purposes we assume it to be zero. Putting the typically trivial value of this to one side, revenue $R_{j}^{k}$ for the $i^{\text {th }}$ peaking plant is hence the product of installed capacity $k^{i}$, the price of that capacity $P^{k}$ (which is expressed in $\$ / \mathrm{MWh}$ ), $t$ being the number of hours in a year as noted earlier in equation (5), and the revenue escalation factor. The value for $R_{j}^{k}$, which will also exactly equals $\bar{F}_{0}$, is a vitally important one as it also defines the 'missing money ${ }^{5}$ in an energy-only market under conditions of intense competition and perfect plant divisibility and availability as Section 6 later demonstrates. It also represents a useful benchmark in helping to establish potential presence of market power abuse and barriers to entry.

\section{Model Results - Generalised Long Run Marginal Cost of Power Generation}

Our PF Model results rely quite crucially on the engineering estimates of capital and maintenance costs of plant. These key variables along with fuel market costs are set out in Table 1 . Note that the parameters have been derived from Worley Parsons (2012), ACIL Tasman (2012) and Frontier Economics (2013) who produce these estimates for the independent market operator (AEMO) and for New South Wales' independent economic regulator. 
Table 1: Engineering \& Cost Parameters for generating plant in the National Electricity Market

\begin{tabular}{|c|c|c|c|c|c|c|c|c|}
\hline \multirow[t]{2}{*}{ Model Variable } & \multirow[t]{2}{*}{ Unit } & \multirow[t]{2}{*}{$i=$} & \multirow{2}{*}{$\begin{array}{r}\text { Black Coal } \\
\text { QLD }\end{array}$} & \multicolumn{2}{|c|}{ Black Coal Brown Coal } & \multirow{2}{*}{$\begin{array}{r}\text { CCGT } \\
\text { VIC } \\
\end{array}$} & \multirow{2}{*}{$\begin{array}{r}\text { CCGT } \\
\text { SA } \\
\end{array}$} & \multirow{2}{*}{$\begin{array}{r}\text { CCGT } \\
\text { QLD } \\
\end{array}$} \\
\hline & & & & NSW & VIC & & & \\
\hline Plant Capacity & MW & $k$ & 1000 & 1000 & 1000 & 400 & 400 & 400 \\
\hline Capacity Factor & $\%$ & $C F$ & 90.0 & 90.0 & $90.0^{\prime}$ & 85.0 & 85.0 & 85.0 \\
\hline Auxillary Load & $\%$ & Aux & 6.0 & 6.0 & 7.0 & 3.0 & 3.0 & 3.0 \\
\hline Thermal Efficiency & $\%$ & $\zeta$ & 39.0 & 39.0 & 28.0 & 50.0 & 50.0 & 50.0 \\
\hline Raw Fuel & $\$ / G J$ & $F$ & 1.00 & 1.42 & 0.40 & 5.00 & 7.00 & 8.00 \\
\hline Variable O\&M & \$/MWh & $v$ & 1.28 & 1.28 & 0.10 & 4.08 & 4.08 & 4.08 \\
\hline Fixed O\&M & \$/MW & $f$ & 52,768 & 52,768 & 36,700 & 10,188 & 10,188 & 10,188 \\
\hline Combustion Emissions & $\mathrm{kg} \mathrm{CO} 2 / \mathrm{GJ}$ & $\dot{\mathrm{g}}$ & 90.2 & 90.2 & 92.0 & 50.6 & 50.6 & 50.6 \\
\hline Fugituive Emissions & $\mathrm{kg} \mathrm{CO} / \mathrm{GJ}$ & $\hat{\mathrm{g}}$ & 8.7 & 8.7 & 8.7 & 18.6 & 18.6 & 18.6 \\
\hline Carbon Price & $\$ / t$ & $C P$ & 7.50 & 7.50 & 7.50 & 7.50 & 7.50 & 7.50 \\
\hline
\end{tabular}

Plant technology types in Table 1 include black and brown coal, Combined Cycle Gas Turbines (CCGT), Wind and Open Cycle Gas Turbines (OCGT). It is worth noting that of the variables listed in Table 1, Raw Fuel (excluding brown coal), Carbon Prices and Capital Costs can be quite volatile and so a regular review of estimates is necessary. ${ }^{6}$ In Australia's National Electricity Market or NEM (i.e. Queensland, New South Wales, Victoria and South Australia), plant types are limited by fuel endowments - Victoria for example does not have any black coal resources while South Australia has largely exhausted all options for future coal. In addition to these parameters, we also require financial and economic parameters, which are presented in Table 2.

Table 2: Financial Economic Parameters

\begin{tabular}{|l|c|r|r|}
\hline Model Variable & Unit & & \\
\hline Inflation & $\%$ & $C P I$ & 2.5 \\
\hline Risk Free Rate & $\%$ & $R_{f}$ & 5.8 \\
\hline Market Risk Premium (Rf-Rm) & $\%$ & $M R P$ & 6.1 \\
\hline Generation Asset Beta & $\#$ & $\beta_{\mathrm{a}}$ & 0.73 \\
\hline Equity Beta Factor VI & $\#$ & $\beta_{\mathrm{VI}}$ & 1.05 \\
\hline Equity Beta Factor IPP & $\#$ & $\beta_{\mathrm{IPP}}$ & 1.58 \\
\hline Tax Rate & $\%$ & $\tau_{c}$ & 30.0 \\
\hline Effective Tax Rate & $\%$ & $\tau_{e}$ & 21.3 \\
\hline 5Yr Interest Rate Swap & $\%$ & $\mathrm{R}_{\mathrm{T}}$ & 3.6 \\
\hline 12Yr Interest Rate Swap & $\%$ & $\mathrm{R}_{\mathrm{T}}$ & 4.5 \\
\hline PF Credit Spread (5 Yr) & bps & $\mathrm{C}_{\mathrm{T}}$ & 250 \\
\hline PF Credit Spread (12 Yr) & bps & $\mathrm{C}_{\mathrm{T}}$ & 300 \\
\hline BBB Credit Spread (5 Yr) & bps & $\mathrm{C}_{\mathrm{T}}$ & 180 \\
\hline BBB Credit Spread (12 Yr) & bps & $\mathrm{C}_{\mathrm{T}}$ & 225 \\
\hline BBB Credit (FFO/I) & times & $\delta_{\mathrm{VI}}$ & $4.0 / 5.0$ \\
\hline BBB Credit (FFO/D) & times & $\omega_{\mathrm{VI}}$ & 0.2 \\
\hline DSCR \& LLCR & times & $\delta_{\mathrm{IPP}}$ & $1.8-2.2$ \\
\hline Sources: PWC (2013), Gray (2013a, 2013b), Simshauser and Nelson (2013).
\end{tabular}

In Figure 1 we present a stylised cost of capital for merchant generation. Debt costs are largely based on 5-12 year bond pricing for varying credit quality. Note the range for project finance runs from about 50-67.5\% (and by chance the results are currently equivalent to bond pricing +/15 basis points). The cost of equity $K_{e}$ has been derived from Simshauser (2013) based on the Capital Asset Pricing Model under atypical capital market conditions. Note that values for $K_{e}$ are largely 'sticky' at our calculated value for any credit quality below BBB. We do not contemplate credit ratings beyond A- due to inherent industry risk, otherwise $K_{e}$ varies according to the Asset Beta in Table 2 as Simshauser (2013) explains. This is based on judgement, and a lack of practical evidence to the contrary. Note that the Weighted Average Cost of Capital is notionally minimised at a BBB credit rating. 
Figure 1: $\quad$ Stylised cost of capital for merchant generation ${ }^{7}$

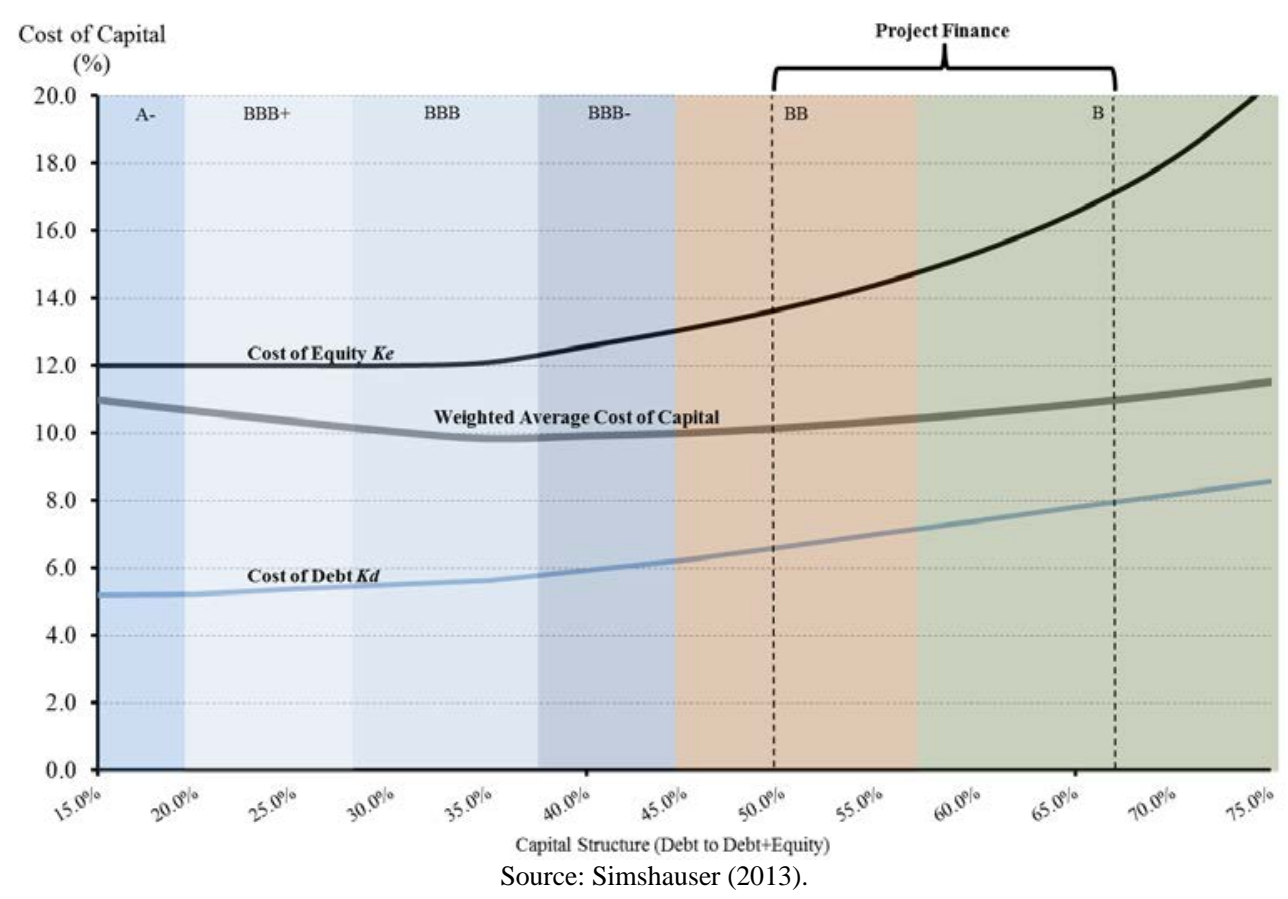

Combining the parameters in Tables 1 and 2 with equations (3) - (22) in our PF model produces generalised long run marginal cost estimates for multiple plant types in total dollars and on a unit cost basis - the latter being more useful for any subsequent comparative analysis. In Figure 2, we present the model results on a unit cost basis under the financing conditions historically activated by merchant power producers using project finance to either develop or acquire a power project for each technology $i$.

Figure 2: $\quad$ PF Model generalised long run marginal cost estimates - Project Financing

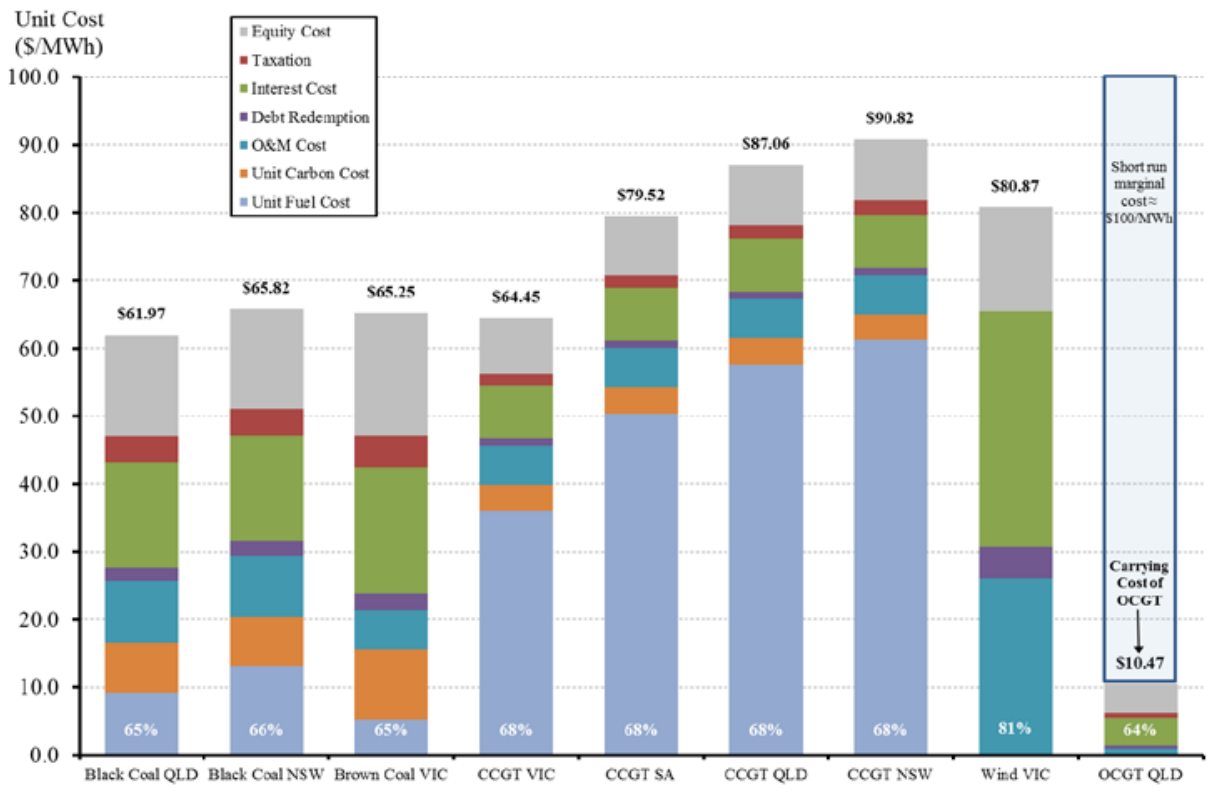

At the bottom of each bar in Figure 2 the "per cent" result relates to the gearing level achievable under energy market equilibrium conditions. So for example, the Black Coal Queensland (QLD) plant has 65 per cent debt within the capital structure. The bars are comprised of the individual cost elements of the plant, starting with Unit Fuel Costs $F^{i}$, Unit Carbon Costs $\left(g^{i} . C P_{j}\right)$ through 
to the Unit Cost of Equity, all of which is expressed in dollars per Megawatt Hour ( $\$ / \mathrm{MWh})$. At the top of each bar is the PF Model's calculated unit price $P^{\varepsilon}$ in which the IRR of the project exactly equals the cost of equity $K_{e}$ while simultaneously meeting all binding credit metrics specified in equation (17) using the Table 2 parameters. To be clear, $P^{\varepsilon}$ is also the generalised long run marginal cost or entry cost for each individual technology. Note also that these unit costs also represent market equilibrium or the 'centre of gravity' for futures contract prices over the long run given an optimal stock and mix of plant. The unit cost of an Open Cycle Peaking (OCGT) plant is expressed as the 'carrying cost of capacity' or $\bar{F}_{0}$ for reasons identified in Section 2.2.

Our alternate business combination results are presented in Figure 3 and arise from producing generalised estimates for plant that have been financed 'on-balance sheet' by an entity with an investment-grade credit rating. The structural changes to unit costs in this instance are limited to capital and taxation, and this is primarily due to binding constraints in equation (17). For ease of comparison, we have included the headline Project Finance results from Figure 2 as the black diamond markers in Figure 3. What this analysis illustrates is that there is no marked benefit in either structure, with the exception of wind plant. ${ }^{8}$ Note however that wind farms are assumed to be backed by an investment-grade Power Purchase Agreement, and thus use different credit metrics (i.e. a DSCR equal to $1.35 \mathrm{x}$ which enables substantially higher gearing) and a constant value for $K_{e}$ (i.e. equivalent to the horizontal section of the $K_{e}$ curve in Figure 1).

Figure 3: $\quad$ PF Model generalised long run marginal cost estimates - Balance Sheet Financing

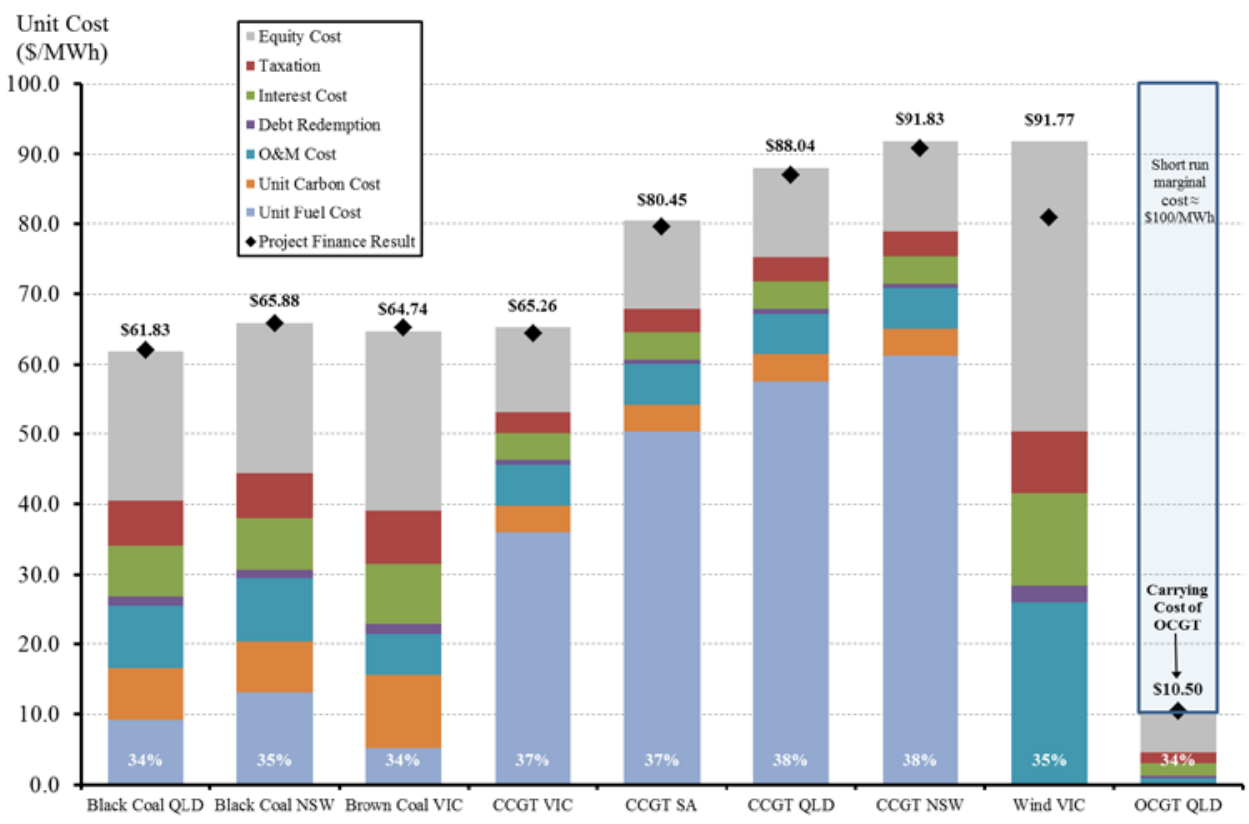

\section{Application to policymaking}

Understanding Normal Profit and the long run marginal cost of production is clearly important for investment decision-making. In our experience, firms in the energy industry use a framework that is consistent with that presented in Section 2 and 3 and extend the revenue lines with power system simulation modelling and so it is not necessary to elaborate further. However, the investment decisions of firms in fixed power assets in the energy industry are influenced quite fundamentally by policy settings - again in our opinion, more so than many other industries given the essential service nature of electricity in the economy and the political economy of electricity tariffs. As such, understanding Normal Profit is important as it will frequently form a pivot point in policy formulation and regulatory settings. 


\subsection{Wholesale market benchmark}

Severe price spikes in gross pool, energy-only, uniform first-price auction wholesale markets typically form a trigger for regulatory or antitrust inquiry. ${ }^{9}$ For policymakers, intervention may be warranted if supranormal profits are being extracted on a sustained basis through generator bidding behaviour in the presence of demonstrable barriers to entry. But episodes of transient price spikes in wholesale markets should not represent an 'automatic' trigger for inquiry let alone policy intervention given the nature of energy-only markets. The reason for this is that there is no stable equilibrium in energy-only markets given a market price cap and a reliability constraint due to the substantial fixed and sunk costs associated with power generation. This can be demonstrated theoretically and through power system simulation modelling.

Proposition I: In an intensely competitive energy-only market with a uniform first-price auction clearing mechanism and perfect plant divisibility and availability, aggregate revenues for the optimal plant mix and for any number of optimal plant technologies will fall short by at least the carrying cost of peaking plant capacity, $\bar{F}_{0}$.

Let the $i^{\text {th }}$ plant have marginal running costs of $\vartheta_{n}$ and total fixed and sunk costs (including the opportunity cost of capital) of $\bar{F}_{n}$. Let price in period $t$ be set on the basis of a uniform, first price clearing auction such that the short run marginal cost of the marginal plant $\vartheta_{n}$ sets price. The intercept between plant $n$ and $n+1$ occurs when:

$\bar{F}_{n}+\vartheta_{n} \cdot t=\bar{F}_{n+1} \cdot+\vartheta_{n+1} \cdot t$

Rearranging this becomes:

$\bar{F}_{n+1}-\bar{F}_{n}=\left(\vartheta_{n}-\vartheta_{n+1}\right) \cdot t$

Under any optimal plant mix for any number of optimal plant technologies, aggregate revenues will always fall short by at least $\bar{F}_{0}$. We provide a mathematical proof for Proposition I in Appendix I and present a static partial equilibrium analysis in Figure 4 and applied results in Table 3 using our modelling outcomes from Section 3. The concept that power system revenues will fall short by fixed capacity costs $\bar{F}_{0}$ when clearing prices are set to marginal cost has long been understood by energy economists and can be traced back to Electrcitie de France's then Chief Economist Marcel Boiteux, and his ground-breaking article on peak load pricing in electricity wholesale markets (Boiteux, 1949). The framework developed by Central Electricity Generating Board of England \& Wales' Chief Economist, Tom Berrie, provides an especially useful static partial equilibrium model of a power system which demonstrates this - although note that we have added a third (Price Duration) chart to Berrie’s (1967) two-chart framework using our Section 3 results from Figure 2. 
Figure 4: $\quad$ Static Partial Equilibrium Model (ex-carbon): Victorian Region FY13

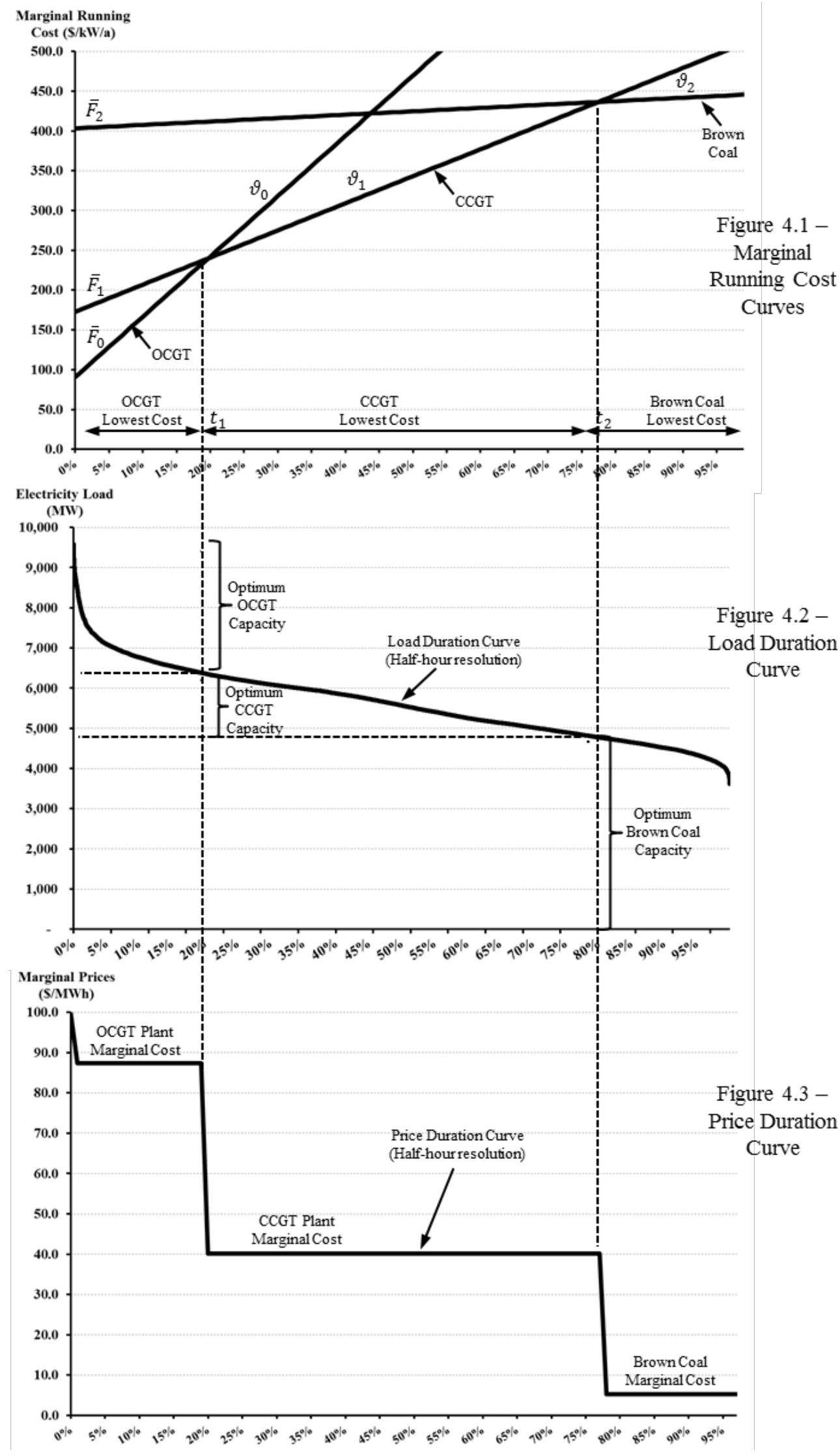


Figure 4.1 illustrates the Marginal Running Cost Curves of the three generating technologies for base (brown coal), semi-base (CCGT) and peaking (OCGT) duties. The y-axis intercept for each technology represents the fixed and sunk costs $\left(\bar{F}_{n}\right)$, and the slope of the curves represents marginal running costs $\left(\vartheta_{n}\right)$. The x-axis measures plant capacity factor $C F_{j}^{i}$ from equation (5). Note intercepts $t_{1}$ and $t_{2}$ identify the point at which the most efficient plant switches to the next technology, given the rich blend of fixed and variable costs in line with equation (24).

Figure 4.2 illustrates a Load Duration Curve. This is a representation of the 17,520 half-hourly electricity load points in a year but ranked in descending order rather than as a time-series, with the y-axis measuring electricity load (MW) and the $\mathrm{x}$-axis measuring 'time exceeded'. ${ }^{10}$ Figure 4.3 is the corresponding Price Duration Curve, that is, the spot price set in each half-hour period in Figure 4.2 under the conditions of a gross pool, energy-only, uniform first-price auction clearing mechanism, with the $y$-axis measuring price and the $\mathrm{x}$-axis also measuring 'time exceeded'.

The Figure 4 static partial equilibrium model assumes firms are free to install perfectly divisible plant capacity with perfect plant availability (and hence no requirement for a reserve plant margin) in any combination that satisfies differentiable equilibrium conditions. The model also assumes a perfect transmission system and hence no constraints on the economic order of plant dispatch. Table 3 sets out all energy production and cost results and notes that the system average spot price of $\$ 55.43 / \mathrm{MWh}$ (i.e. the average of results in Figure 4.3) falls short of system average cost of $\$ 66.04 / \mathrm{MWh}$ by the amount equivalent to $\bar{F}_{0}$ - that is, $\$ 10.60 / \mathrm{MWh}$ (per Figure 2).

Table 3: Static Partial Equilibrium Results given Perfect Plant \& Transmission System Availability

\begin{tabular}{lccccccc}
\hline Plant Type & $\begin{array}{c}\text { Capacity } \\
(\mathrm{MW})\end{array}$ & $\begin{array}{c}\text { Production } \\
(\mathrm{GWh})\end{array}$ & $\begin{array}{c}\text { Fixed Costs } \\
(\mathbf{\$ m})\end{array}$ & $\begin{array}{c}\text { Running Costs } \\
(\mathbf{\$ m})\end{array}$ & $\begin{array}{c}\text { Total Costs } \\
(\mathbf{\$ m})\end{array}$ & $\begin{array}{c}\text { Avg Unit Cost } \\
(\$ / \mathrm{MWh})\end{array}$ & $\begin{array}{c}C F_{j}{ }^{i} \\
(\%)\end{array}$ \\
\hline Brown Coal & 4,853 & 38,167 & 1,957 & 200 & 2,157 & 56.52 & 90 \\
CCGT & 1,544 & 9,067 & 267 & 363 & 630 & 69.50 & 67 \\
OCGT & 3,191 & 1,968 & 290 & 172 & 462 & 234.61 & 7 \\
\hline Total & 9,588 & 49,202 & 2,514 & 735 & 3,249 & 66.04 & 59 \\
Average Spot Price & & & & & 55.43 & \\
\multicolumn{2}{l}{\begin{tabular}{l} 
Diff (Avg Unit Cost less Avg Spot Price) \\
\hline
\end{tabular}}
\end{tabular}

Once the assumptions of perfect plant divisibility and availability are relaxed, Average Unit Cost can be expected to rise, and Average Spot Price can be expected to fall, as discrete power plant blocks are added (i.e. lumpy plant entry) and requisite excess capacity (i.e. additional OCGT plant) is purposefully added to ensure power system reliability constraints are met.

Simultaneously, a Value of Lost Load or Market Price Cap is introduced (i.e. the spot price that applies during shortages) and in Australia's National Electricity Market is $\$ 13,100 /$ MWh. This offsets some, but not all, additional costs and only if the optimal number of blackouts occurs annually within the reliability constraint as Simshauser (2008) demonstrates.

\subsection{Discussion}

The key issue arising from the quantitative plant-specific results in Section 3 and the aggregate industry result from Section 4.1 is that even with the perfectly optimal plant mix and a zero reserve margin, no plant has any prospect of earning Normal Profits when conditions reflect intense competition. From a policymaking perspective, the question that follows is does this actually matter? After all, traditional welfare economics commences with the presumption that economic efficiency is maximised when prices are set at marginal cost. However, the model of perfect competition also assumes constant or decreasing returns to scale and that clearing prices result in Normal Profits to efficient firms. 
In industries with increasing returns to scale, where fixed and sunk costs are non-trivial, and where short run marginal costs are very low (or zero in the case of renewable energy ${ }^{11}$ ), clearly a problem exists as Figure 4 and Table 3 demonstrate. Varian (1996) notes that under such conditions, persistent uniform pricing at industry short run marginal cost is not economically viable. In a terminal industry, this may not warrant further consideration. But the electricity industry is not terminal. While it is true that electricity demand has contracted marginally over the past 3-4 years, longer run projections exhibit mild but nonetheless positive growth. Furthermore, existing plant is aging and will one day need replacement, and new plant will be required to meet renewable policy objectives. Accordingly, policymakers cannot ignore how fixed and sunk costs are treated by policy changes. It is not the role of policymakers to deliver profits to power companies. Nor however is it their role to set policies that constrain the ability of firms to earn Normal Profit over the business cycle.

How does this translate into practice? Section 4.3 provides a useful applied example but in summary, spot price outcomes in an intensely competitive energy-only market with a reliability constraint cannot be considered a pragmatic benchmark for which to devise policy settings. Generators persistently bidding at marginal running costs will result in prices that clear below system average cost as Figure 4 and Table 3 demonstrate. Simshauser (2008) demonstrated that when the assumptions of perfect plant divisibility and availability are relaxed, there is not a stable equilibrium that will calibrate supply to demand in a manner consistent with stated reliability standards in the long run (absent extremely high market price caps). Further, as Bidwell and Henney (2004, p22) explain, even with high wholesale market price caps, a stable financial equilibrium could only be reached if the physical power system is operating 'near the edge of collapse'. At some point generator bidding must deviate from short run marginal cost or blackout-induced Market Price Cap events must increase in frequency. Benchmarks for policymaking must therefore turn to plant and fleet-wide generalised long run marginal cost estimates, respectively.

\subsection{Application to wholesale markets}

To demonstrate the importance of these concepts, we consider how benchmarks of Normal Profit can be largely ignored by economists when assessing the market power of incumbent generators in wholesale markets. Mountain (2013) concludes that the imposition of carbon pricing from 2012 improved the profitability of all generators, with wholesale prices more than doubling and gains extracted after power generators exercised market power in the Australian market. The analysis compared spot prices over a nine month period before and after the carbon policy change - nine months being the limit of data available at the time. This type of analysis can be reproduced - Table 4 draws on the relevant spot market data from the independent market operator, using Victorian region data as an example. ${ }^{12}$

Table 4: Victorian average spot prices Period-on-Period Change (FY12 vs. FY13)

\begin{tabular}{|c|c|c|c|c|c|c|}
\hline Month & $\begin{array}{r}\text { FY13 Spot } \\
\text { Incl. CO2 } \\
(\$ / \mathrm{MWh}) \\
\end{array}$ & $\mathrm{CO}_{2}$ Price & $\begin{array}{r}\text { Average Carbon } \\
\text { Intensity } \\
\left(\mathrm{CO}_{2} / \mathrm{MWh}\right) \\
\end{array}$ & $\begin{array}{r}\text { FY13 Adj. } \\
\text { Excl. CO2 } \\
(\$ / M W h) \\
\end{array}$ & $\begin{array}{r}\text { FY12 Spot } \\
\text { Pre- } \mathrm{CO}_{2} \\
(\$ / \mathrm{MWh}) \\
\end{array}$ & $\begin{array}{r}\text { Spot Price } \\
\text { Difference } \\
(\$ / \mathrm{MWh}) \\
\end{array}$ \\
\hline Jul & 73.46 & 23.00 & 1.166 & 46.65 & 29.49 & 17.16 \\
\hline Aug & 55.76 & 23.00 & 1.182 & 28.57 & 29.95 & -1.38 \\
\hline Sep & 53.48 & 23.00 & 1.213 & 25.58 & 26.98 & -1.40 \\
\hline Oct & 51.27 & 23.00 & 1.225 & 23.09 & 23.61 & -0.52 \\
\hline Nov & 77.18 & 23.00 & 1.244 & 48.57 & 26.58 & 21.99 \\
\hline Dec & 52.18 & 23.00 & 1.258 & 23.25 & 22.18 & 1.07 \\
\hline Jan & 54.27 & 23.00 & 1.237 & 25.81 & 24.03 & 1.78 \\
\hline Feb & 53.59 & 23.00 & 1.187 & 26.29 & 25.85 & 0.44 \\
\hline Mar & 52.31 & 23.00 & 1.221 & 24.24 & 23.70 & 0.54 \\
\hline Avg & 58.17 & 23.00 & 1.215 & 30.23 & 25.82 & 4.41 \\
\hline
\end{tabular}


The time-weighted average spot price for the first nine months of FY13 in Table 4 is \$58.17/MWh and the Carbon Adjusted FY13 spot price (column 5) averages \$30.23/MWh. This adjusted price has been derived by stripping the estimated carbon impact (i.e. $\mathrm{CO}_{2}$ price $\mathrm{x}$ Average Carbon Intensity) from FY13 spot prices, such that $\$ 58.17-(\$ 23 / t \times 1.215 t)=$ \$30.23MWh. ${ }^{13}$ The final column compares the adjusted FY13 spot price with the FY12 spot price, which results in a difference of $\$ 4.41 / \mathrm{MWh}$. This differential is identified as a gain to the profitability of generators since wholesale price rises exceeded carbon costs. ${ }^{14}$ Mountain (2013) concluded that such an outcome is not consistent with a competitive market, while the Energy Users Association of Australia added that the regulator should be granted greater scrutiny over generator bidding. ${ }^{15}$

There are many reasons why a regulator might be granted greater scrutiny over generator bidding - but our Table 4 analysis does not comprise one of them as it over-simplifies a very complex set of spot market outcomes. It ignores the role and effects of (1) short run weather on aggregate demand, (2) generator outages on aggregate supply, and (3) volumetric losses of individual plants - all of which are known to be non-trivial. Above all though is the suitability of the initial benchmark.

Using this analysis in Table 4 is, in our opinion, inappropriate for the reasons outlined in Section 4.2. Analysing against a Period-on-Period unit price benchmark that is demonstrably below system average cost, or worse still, equal to system short run marginal cost in an industry with substantial fixed and sunk costs runs a high risk of producing a Type II error as Figure 4 and Table 3 demonstrate. Table 3 noted that the perfectly optimal plant mix for the Victorian region would produce aggregate annual costs (including Normal Profit) of \$3,249 million. The FY12 spot price from Table 4 was $\$ 25.82$ and annual output from Table 3 was 49,202GWh meaning that total spot revenues earned by plant was $\$ 1,270$ million. As a result during the 'base year' of the analysis, generators incurred economic losses (compared to spot prices) of at least $\$ 1,900$ million. ${ }^{16}$ Regardless, a nine month period is too short to draw meaningful conclusions on the levels of industry competition and profits of a fleet of capital-intensive power stations with useful lives spanning several decades.

The Table 4 analysis lacks a pragmatic and theoretically robust Normal Profit benchmark. To remedy this, we have re-run the PF Model under conditions of a zero carbon price for the relevant base plant in Victoria. We also analyse the financial viability of highly efficient new entrants in the PF Model whereby the unit price $P^{\varepsilon}$ is set as an input equivalent to the FY12 value in Table 3 rather than that derived by equation (21). Figure 5 illustrates these results. 
Figure 5: $\quad$ Comparison of generalised long run marginal costs with Table 4 FY12 spot prices

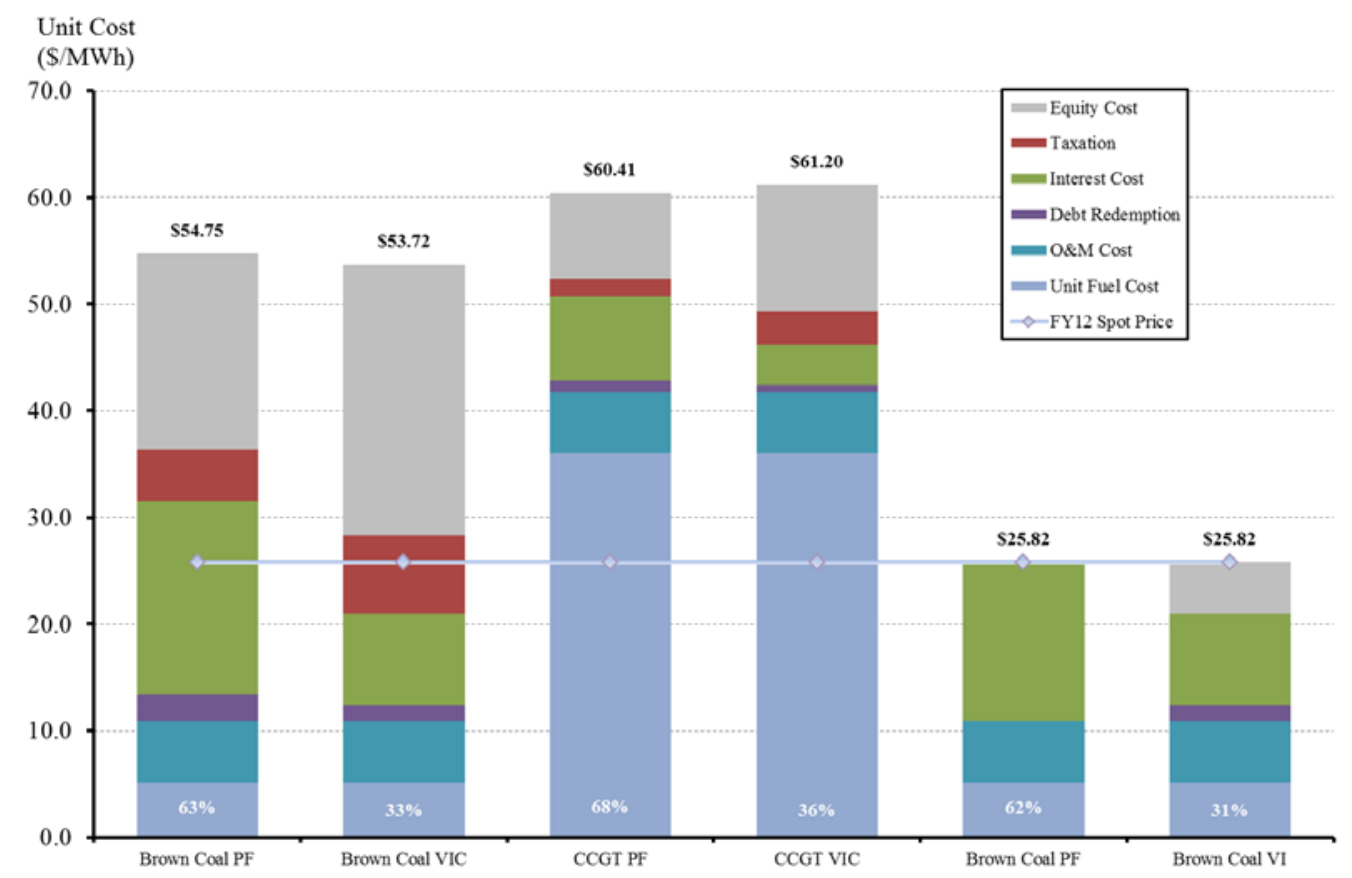

The horizontal line in Figure 5 represents the FY12 actual spot price of \$25.82/MWh. This is then compared with brown coal and CCGT plant entrants under the two business combinations, project finance (PF) and a vertically integrated entity (VI) using BBB credit-rated debt. The first two bars show the brown coal result for PF and VI, while the second two bars show the equivalent results for a CCGT plant. The final two bars illustrate the financial out-workings that coal plant (i.e. the lowest cost entrant excluding $\mathrm{CO}_{2}$ ) would face if exposed to a convergent electricity price of \$25.82/MWh.

From inspection of the final two bars in Figure 5 it is evident that the Brown Coal PF plant is completely bankrupt and unable to pay its interest expense, let alone the principal. There are no equity returns whatsoever. The Brown Coal VI plant, due to its substantially lower gearing level, is theoretically able to withstand such a price and, assuming its BBB credit rating is held constant, retains its financial stability. In reality the credit rating will have been stripped (meaning debt covenants will have been breached requiring remedy), no taxation will be paid (due to the plant making sizable taxation losses) and the running cash yield would equate to $1.8 \%$ compared to $10.0 \%$ when the plant is earning a Normal Profit.

Our quantitative results in Figure 5 make it clear that quasi-rents (partial contributions to fixed costs) commence when prices exceed \$28-\$35/MWh. But at any price below \$53/MWh, brown coal generators are incurring 'economic losses'. For a CCGT plant with gas supplied at $\$ 5 / G J$, short run marginal costs are not recovered until prices exceed $\$ 40 / \mathrm{MWh}$, let alone fixed cost recovery. Our generalised cost estimates paint a radically different picture to that expressed in Table 4 in which competition is thought to be inadequate with generators extracting windfall gains.

How should a policymaker react to such conflicting information? Real world events that occurred in the period immediately preceding the carbon tax provide appropriate guidance. The two largest brown coal plants in Victoria, Loy Yang ${ }^{17}$ and Hazelwood ${ }^{18}$ were both recipients of emergency recapitalisations in June 2012 - of $\$ 1.2$ billion and $\$ 650$ million respectively. Absent this, in our professional opinion both plants would have experienced financial distress. Structural adjustment assistance packages were issued to brown coal plant by the Australian Government in 
an attempt to moderate the most acute effects of the carbon price implementation for reasons explained in Simshauser and Nelson (2012). ${ }^{19}$ Yet in spite of this, ex post emergency recapitalisations were still necessary. Loy Yang for example incurred an equity write-off of c. $\$ 400$ million or $40+\%$ of the post-acquisition equity value of $\$ 950$ million - and this was after accounting for structural adjustment assistance. The third largest brown coal plant in Victoria, Yallourn also incurred write-downs of $\$ 245$ million. ${ }^{20}$

Our observation is that these outcomes were not a surprise to the industry. Table 4 noted that spot electricity prices in the pre-carbon environment were \$25.82/MWh. They had in fact averaged about $\$ 27$ throughout FY11 and FY12, and as a result, many plants were in the early stages of financial distress. That the incumbent plants lasted almost two years without defaulting on project debt was due to commodity hedge contracts signed in prior years under considerably more favourable market circumstances. However, as these hedge contracts progressively matured and were replaced with lower value hedge contracts, emergency recapitalisations became essential. Using the Table 4 FY12 spot price result of \$25.82 as an efficient benchmark and concluding subsequent changes represented evidence of inadequate competition and windfall gains, while those prices were simultaneously driving generators to a state of financial distress, is not credible.

During FY13, the carbon price could be said to have been transmitted at a pass-through rate of $116 \%$ of the average industry $\mathrm{CO}_{2}$ intensity ${ }^{21}$ - but only after holding all other variables strictly constant. That is, given a carbon price of $\$ 23 / \mathrm{t}$, and emissions intensity of $1.215 \mathrm{t} / \mathrm{MWh}$, one might expect an increase of (\$23/t x 1.215t =) \$27.94/MWh whereas FY13 spot prices increased by $\$ 32.35 / \mathrm{MWh}$ to $\$ 58.17 / \mathrm{MWh}$. So under these conditions, generator losses could be said to be lower than in FY12 provided their output levels are held constant (although data from the independent market operator reveals a substantial contraction in brown coal production, from 39,856 GWh to 34,112 GWh). ${ }^{22}$ Figure 6 illustrates the comparative impact with the PF Model run using a $\$ 23 /$ t carbon price.

\section{Figure 6: $\quad$ Generalised long run marginal costs vs. Table 4 FY13 carbon-inclusive spot prices}

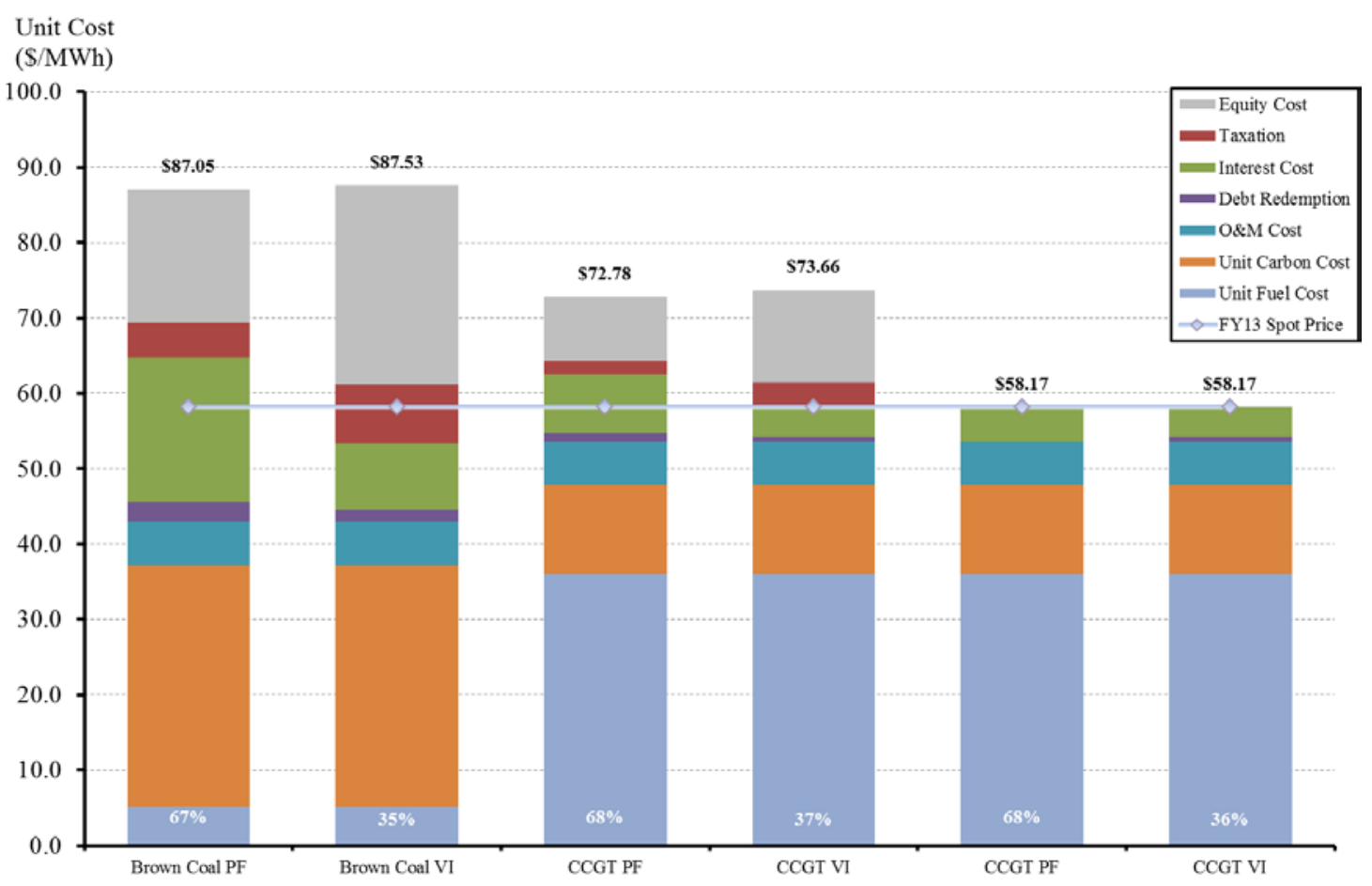


In this instance, the Normal Profit benchmarks change substantially, with brown coal plant rising to $\$ 85-88 / \mathrm{MWh}$, and CCGT plant at $\$ 72-\$ 74 / \mathrm{MWh}$. In a post-carbon price analysis, once again, there is no evidence that windfall profits are being extracted. The final two bars in Figure 6 focus on CCGT plant as they represent the optimal plant for base duties given a price on carbon. The CCGT PF plant in Figure 6 is in manifest breach of its financing covenants - unable to repay its full interest cost let alone principal repayment. The CCGT VI is however able to financially withstand the lower price as was its Brown Coal VI counterpart in Figure 5 - although again the firm would be stripped of its investment grade credit rating and would be in breach of debt covenants. The running cash yield of the plant is just $0.2 \%$ compared to $11.2 \%$ when the plant is producing Normal Profits.

One potential criticism of the analysis thus far is that the examination of market power occurs ex post. However, analysing the price of call option contracts from the futures market provides ex ante guidance. In particular, if market power abuse is present then we would expect to see sustained increases in the price of $\$ 300$ call option contracts across the three-year forward curve at levels above our unit estimate for $\bar{F}_{0}$. But as with our analysis of base prices, year-ahead futures prices for $\$ 300$ call options in Victoria during 2013 were $\$ 4.35 / \mathrm{MWh}$ - less than half of our unit value for $\bar{F}_{0}$ of $\$ 10.47 / \mathrm{MWh}$. Once again, there is little evidence of windfall gains.

\section{Concluding Remarks}

Policymakers and regulators governing competitive power markets, particularly those based on a gross pool, energy-only market designs as exists in Australia, Texas, New Zealand, Singapore, Alberta (Canada) and Europe amongst others, face an interesting dilemma. Our Proposition I and associated static partial equilibrium model in Section 4 demonstrates that under conditions of intense competition, perfect plant availability and divisibility with no transmission constraints, energy-only markets result in clearing prices which are not economically viable in the long run. When these simplifying assumptions are relaxed, things get worse, not better. One option, operating a power system on 'the edge of collapse' as Bidwell and Henney (2004, p22) explain, is not politically viable. This means that bidding must, by definition, deviate from strict (short run) marginal cost at some stage. The judgement of the regulator is to determine whether deviations represent a sustained departure in the presence of barriers to entry and are a potential abuse of market power, or whether it merely represents quasi rents and a partial inter-temporal contribution towards substantial fixed and sunk costs. All too often, regulatory inquiry is static and ignores the essential time dimension. Policymakers in Australia and the regulator in Alberta (respectively) understand this balance:

Without affording electricity generators the opportunity to submit dispatch bids or rebids above marginal cost, new capacity would fail to enter the market and the market would become vulnerable to periods of inadequate supply. Wholesale market price volatility and the ability of electricity generators to- from time to time- offer electricity into the market at prices above marginal cost (sometimes even as high as the market price cap) is entirely consistent with the design of [Australia's] National Electricity Market... (AEMC, 2013, p. 65)

...wholesale price volatility and price polarity (periods of low prices interspersed with shorter periods of high prices) are an expected outcome in an electricity market such as Alberta's and consistent with effective competition. In fact, these price signals promote innovation and economic efficiency... (MSA, 2012, p.1).

An important input to the judgement required of policymakers and regulators was presented in Section 2 - a theoretically robust measure of Normal Profit as a suitable 'benchmark' for which to gauge activity over the business cycle. Our PF Model focused on two business combinations and found that there was little difference in the ultimate long run marginal cost estimate, although 
the differences in the thresholds for bankruptcy were marked. This analysis was then applied in an ex post analysis of base energy prices against pragmatic estimates for the long run marginal cost of base plant, and an ex ante analysis of call option prices against the carrying cost of peaking plant, using Victoria as a case in point.

Prima facie it may be tempting to argue that our Normal Profit benchmark is overstated because it ignores the fact that the actual plant mix is different from optimality, or that existing plant is aged/depreciated or holds special resource endowments (such as long-dated fuel contracts at below market rates). On the other hand, existing plant owners may argue that our benchmark understates the real costs of existing businesses which were developed or acquired at higher cost (i.e. when turbine prices were higher in real terms) or fail to account for the industrial/labour market constraints.

Neither set of arguments holds in the long run. If profit benchmarks are raised to inefficient levels and new entrants do not enter and compete away the available supranormal profit over the business cycle, then material barriers to entry may exist and policy intervention may be warranted where market power is being exercised. On the other hand, if profit benchmarks are set to suboptimal levels, neither incumbents nor entrants will find it profitable in the long run which has implications for reliability and an inevitable (and typically unwelcome) price correction of significance over time. Ultimately, a pragmatic Normal Profit benchmark must be forward looking, not only with respect to the cost of capital, but of what capital needs to be deployed to meet incremental demand or replace retiring plant.

\section{References}

ACIL Tasman, (2012), "Fuel cost projections”, Report to AEMO, ACIL Tasman Publication, Brisbane. Available at www.aemo.com.au

AEMC: Australian Energy Market Commission (2013), “Final Rule Determination: potential generator market power in the NEM”, AEMC Publication, Sydney. Available at www.aemc.gov.au

Berrie, T. (1967), “The economics of system planning in bulk electricity supply”, Electrical Review, Vol. 22, No.2, pp. 425-428.

Besser, J., Farr, J. and Tierney, S. (2002), “The political economy of long-term generation adequacy: why an ICAP mechanism is needed as part of standard market design”, Electricity Journal, Vol.15, No.7, pp 5362.

Bidwell, M. and Henney, A. (2004), “Will Neta ensure generation adequacy?”, Power UK, Vol. 122, pp. 10-26.

Boiteux, M. (1949), “La tarification des demandes en pointe: Application de la theorie de la vente au cout marginal”, Revue Generale de l'Electricite, Translated by H. Izzard in Journal of Business, Boiteux, M. 1960, 'Peak load pricing', Journal of Business, Vol.33, No.2, pp. 157-80.

Brealey, R., Myers, S. and Allen, F. (2011), Principles of Corporate Finance, Second Edition, McGraw Hill, Sydney.

Bushnell, J. (2005), “Electricity Resource Adequacy: matching policies and goals”, Electricity Journal, Vol.18, No.8, pp. 11-21.

Cramton P. and Stoft, S. (2006), “The convergence of market designs for adequate generating capacity with special attention to the CAISOs resource adequacy problem”, Cambridge, MA: Center for Energy and Environmental Policy Research.

de Vries, L. (2003), “The instability of energy-only electricity markets”, Research Symposium: European Electricity Markets, The Hague, September 2003. 
de Vries, L. (2004), "Securing the public interest in electricity generation markets, the myths of the invisible hand and the copper plate", PhD Dissertation, Delft University of Technology, The Netherlands.

de Vries, L. And Heijnen, P. (2008), “The impact of electricity market design upon investment under uncertainty: the effectiveness of capacity mechanisms”, Utilities Policy, Vol.16, pp. 215-227.

Finon, D. (2008), "Investment risk allocation in decentralised markets: the need of long-term contracts and vertical integration”, OPEC Energy Review, Vol.32, No.2, pp. 150-183.

Finon, D. and Pignon, V. (2008), "Electricity and long-term capacity adequacy: the quest for regulatory mechanisms compatible with electricity markets”, Utilities Policy, Vol.16, pp.143-158.

Frontier Economics, (2013), "Input assumptions for modelling wholesale electricity costs - draft report prepared for IPART”, Frontier Economics Publication, April, Melbourne.

Gray, S. (2013), "Evidence on the required return on equity from independent expert reports”, SFG Consulting, Mimeo., Brisbane.

Gray, S. (2013b), “The required return on equity since the global financial crisis”, SFG Consulting, Mimeo., Brisbane.

Joskow, P. (2006), “Competitive electricity markets and investment in new generating capacity”, AEIBrookings Joint Centre for Regulatory Studies, Working Paper No.06-14.

Joskow, P. (2008a), “Lessons learned from electricity market liberalisation”, The Energy Journal, Vol.29, No.2, pp. 9-42.

Joskow, P. (2008b), “Capacity payments in imperfect electricity markets: need and design”, Utilities Policy, Vol.16, pp. 159-170.

Lintner, J. (1965), "The valuation of risk assets and the selection of risky investment in stock portfolios and capital budgets”, Review of Economics and Statistics, Vol.47, Feb, pp. 13-37.

MSA: Market Surveillance Administrator, (2012), State of the Market Report 2012, MSA Publication, 10 December 2012.

Mountain, B. (2013), “The impact of emission prices on electricity prices in the National Electricity Market”, Carbon Market Economics Publication, Melbourne. Available at www.carbonmarkets.com.au Accessed 20 June 2013.

Nelson, T., Orton, F. and Kelley, S. (2012), “A literature review of economic studies on carbon pricing and Australian wholesale electricity markets”, Energy Policy, Vol.49, pp. 217-224

Nelson, J. and Simshauser, P. (2013), “Is the Merchant Power Producer a Broken Model?”, Energy Policy, Vol. 53, pp.298-310.

Neuhoff, K. and De Vries, L. (2004), “Insufficient incentives for investment in electricity generation”, CMI Working Paper 42, Cambridge.

Newbery, D. (2006), “Market Design”, EPRG Working Paper No. 0515, University of Cambridge. Available at http://www.eprg.group.cam.ac.uk/category/publications/working-paper-series

Oren, S. (2003), "Ensuring generation adequacy in competitive electricity markets”, University of California Energy Institute - Energy Policy \& Economics 007, University of California, Berkley.

Peluchon, B. (2003), "Is investment in peak generation assets efficient in a deregulated electricity sector?”, Research Symposium: European Electricity Markets, The Hague, September 2003. 
Roques, F., Newbery, D. and Nuttall, W. (2005), "Investment incentives and electricity market design: the British experience”, Review of Network Economics, Vol.4, No.2, pp. 93-127.

PwC: Pricewaterhouse Coopers, (2013), "Guidance on the cost of capital for new plant entry to the National Electricity Market”, PwC Report to AGL Energy Ltd, Sydney.

Salmi, T. and Virtanen, I. (1997), "Measuring the Long-Run Profitability of the Firm; A Simulation Evaluation of the Financial Statement Based IRR Estimation Methods", Acta Wasaensia, No.54, University of Vaasa, Finland. Available at http://www.uwasa.fi/ ts/smuc/smuc.html .

Schweppe, F., Caramanis, M., Tabors, R. And Bohn, R. (1988), Spot pricing of electricity, Kluwer Academic Publishers, London.

Sharpe, W. (1964), “Capital Asset Prices: a theory of market equilibrium under conditions of risk”, Journal of Finance, Vol.19, Sept, pp. 425-442.

Simshauser, P. (2008), "The dynamic efficiency gains from introducing capacity payments in the National Electricity Market”, Australian Economic Review, Vol.41, No.4, pp. 349-370.

Simshauser, P. (2009), “On emissions trading, toxic debt, and the Australian power market”, Electricity Journal, Vol.22, No.2, pp. 9-29.

Simshauser, P. (2010), "Vertical integration, credit ratings and retail price settings in energy only markets: navigating the Resource Adequacy problem”, Energy Policy, Vol.38, Nov, pp. 7427-7441.

Simshauser, P. (2013), “The cost of capital for power generation in atypical market conditions?”, AGL Applied Economic \& Policy Research Working Paper No.39, Brisbane.

Simshauser, P. and Doan, T. (2009), "Emissions trading, wealth transfers and the wounded-bull scenario in power generation”, Australian Economic Review, Vol.42, No.1, pp. 64-83.

Simshauser, P. and Nelson, T. (2012), "The second-round effects of carbon taxes on power project finance”, Journal of Financial Economic Policy, Vol.4, No.2, pp. 104-127.

Steed, J., \& Laybutt, C. (2011). Merchant Utilities: Who gets the missing money? Sydney: J.P. Morgan Securities Australia.

Wen, F., Wu, F. and Ni, Y. (2004), “Generation capacity adequacy in the competitive electricity market environment”, Electrical Power \& Energy Systems, Vol.26, pp. 365-372.

Worley Parsons (2012), “Cost of Construction - New Generation Technology”, Report to AEMO, Worley Parsons Publication, Melbourne. Available at www.aemo.com.au 


\section{Appendix I: Mathematical Proof of Missing Money in Energy-Only Markets}

Under any optimal plant mix for any number of optimal plant technologies, aggregate revenues will always fall short by at least $\bar{F}_{0}$

\section{Proof by mathematical induction:}

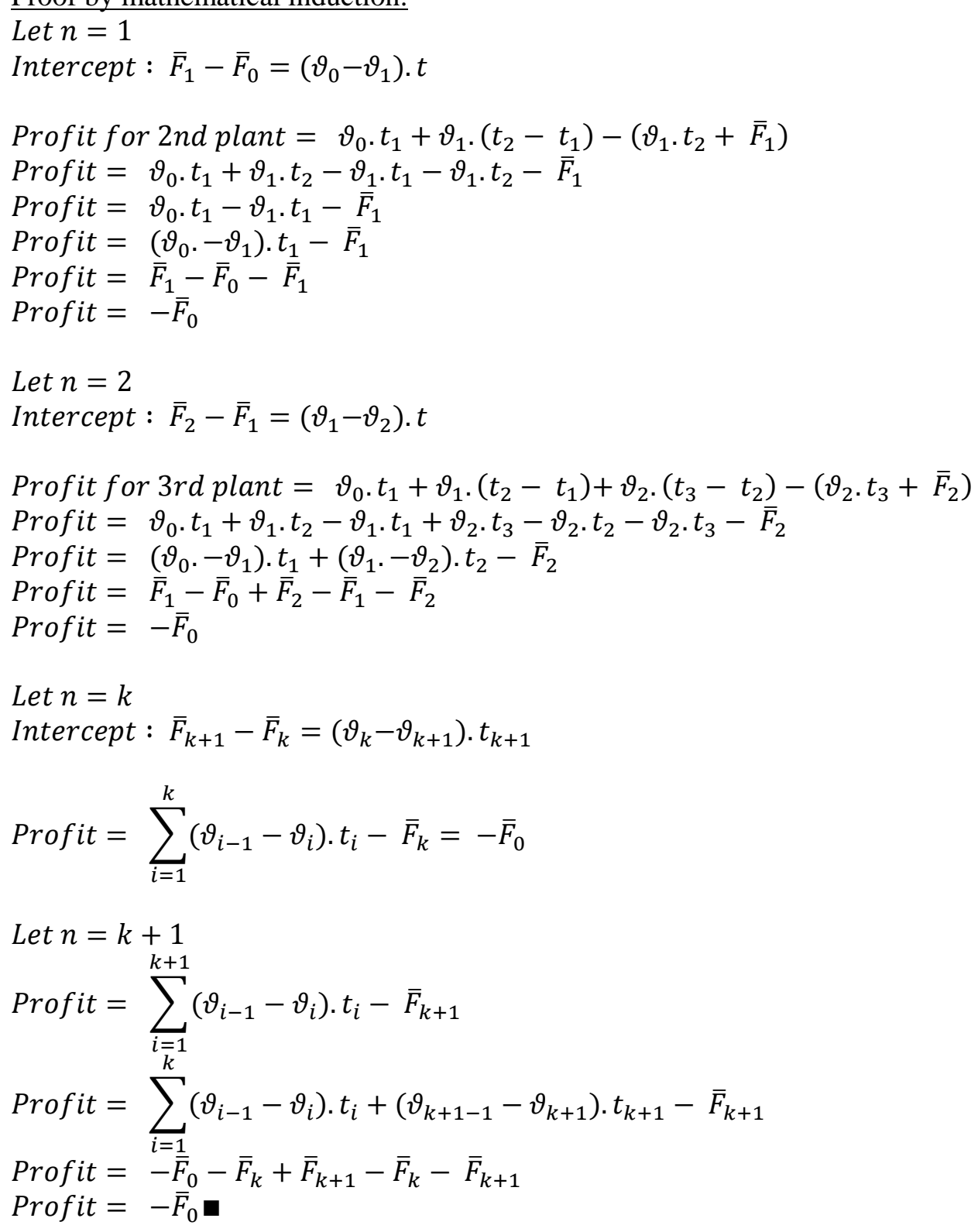

\footnotetext{
${ }^{1}$ See for example Brealey, Myers and Allen (2011, pp 109-115) for a discussion of the conditions where IRR calculations deviate from NPV calculations.

${ }^{2}$ See Frontier Economics (2013) at pp31-35 for a useful explanation of learning curves as they relate to power generation technologies.

${ }^{3}$ This factor is based on average ancillary services revenues as a percentage of overall energy market revenues.

${ }^{4}$ The derivation of the constant term 3600 is: 1 Watt $=1$ Joule per second and hence 1 Watt Hour $=3600$ Joules.

${ }^{5}$ The term 'missing money' was first discussed by Cramton and Stoft (2006), and later Joskow (2006), and describes a situation whereby market price caps (set low to constrain market power) adversely affect average clearing prices thus resulting in inadequate returns to investors in generation plant. Steed and Laybutt (2011) identify c.\$6 billion in 'missing money' in the National Electricity Market from 2000-2010 even with a market price cap of \$10,000/MWh.

${ }^{6}$ Reviewing gas cost estimates is particularly important in the Australian case due to the rapidly changing dynamics occurring in the market for natural gas, viz. the development of LNG terminals and the shift in pricing from a domestic 'cost plus' market to international gas pricing. Capital costs can also be quite volatile due to supply-imbalances in plant manufacturing market, and changes in exchange rates due to the dominance of imported mechanical and electrical equipment.
} 
${ }^{7}$ The cost of capital in Figure 1 is based on a 'Vanilla WACC' calculation, that is, a post-tax cost of equity and a pre-tax cost of debt. Post-tax pre-financing cash flows are discounted by the Vanilla WACC. However, in this article, all cash flows are post-tax and postfinancing, and so are discounted by the post-tax cost of equity.

${ }^{8}$ From this one would conclude that all wind turbines should be project financed rather than financed on-balance sheet. However, our PF Model has one significant limitation in this regard - it does not model portfolios of plant at the enterprise level. In practice, credit rating agencies treat half of the PPA's present value as 'synthetic debt' on the balance sheet of the counterparty who writes the instrument. This in turn has a real opportunity cost to vertically integrated firms - since their level of total corporate debt must be modified downwards accordingly, and so the apparent gains from writing PPAs over balance sheet financings are partially illusory.

${ }^{9}$ For example the Australian Energy Regulator routinely investigates every price spike above \$5,000 regardless of whether average spot prices are approaching Normal Profit levels.

${ }^{10}$ In this instance, live FY13 half-hourly load data from the Victorian region has been used.

${ }^{11}$ While many renewable energy technologies have zero or negligible fuel costs, Biomass plant is a notable exception.

${ }^{12}$ Mountain (2013) analyses production-weighted spot prices for all generation plant types. Here, we focus on the time-weighted spot price in Victoria and compare these with our estimates of brown coal plant costs. Mountain's (2013) FY13 production-weighted price is $\$ 58 / \mathrm{MWh}$ and FY12 is $\$ 26 / \mathrm{MWh}$ - which is consistent with the result in Table 4 (results in columns 1 and 5).

${ }^{13}$ The average carbon intensity of $1.215 \mathrm{t}$ has been derived from AEMO market data. This analysis assumes the carbon price was passed-through at the industry's average carbon intensity for the reasons explained Nelson, Orton and Kelley (2012). One implication of this is that all brown coal generators are incurring losses on carbon costs because their $\mathrm{CO}_{2}$ intensities of $1.28 \mathrm{t}-1.55 \mathrm{t} / \mathrm{MWh}$ are above the average intensity of 1.215t/MWh.

${ }^{14}$ See in particular Mountain (2013, p.24).

${ }^{15}$ See in particular the EUAA Media Statement “Power generation prices need closer monitoring” - released 27 June 2013. Available at www.euaa.com.au.

${ }^{16}$ In reality, hedge contracts struck at higher values in preceding periods would have reduced these loses materially. On the other hand, the Victorian region is currently oversupplied and as such economic losses would have been greater than implied given the additional capital stock deployed.

${ }^{17}$ AGL Energy acquired 100\% of the 2200MW Loy Yang power station and coal mine in June 2012. The implied enterprise value was $\$ 3.1$ billion or $\$ 1410 / \mathrm{kW}$. AGL Energy raised $\$ 1.5$ billion from the debt and equity capital markets of which $\$ 1.2$ billion was used to recapitalise the project's existing debt tranches. There is little doubt that when those debt tranches matured, refinancing would have only been partially successful and additional equity injections would have been required.

${ }^{18}$ The parent entity of Hazelwood power station, GDF Suez, injected $\$ 650 \mathrm{~m}$ of 'rescue capital' into its project debt structure using an intercompany loan during the last week of June 2012. Hazelwood had been unable to secure bank funding. For further details, see the Australian Financial Review at http://www.afr.com/p/national/rescue for power station xk639CP4CyQuJIp9ndewYP

${ }^{19}$ See Mountain (2013) for details of the structural adjustment assistance.

${ }^{20}$ These write-offs at the three largest brown coal plants occurred because of a legal obligation Company Directors have to ensure that asset values are reported as fair and reasonable under Sections 295-297 of Australia’s Corporations Act 2001 (Cth). Sections 296 and 297 in particular require the application of Australian Accounting Standard AASB136 - Impairment of Assets. Failure to account for a fair and reasonable carrying value of fixed assets exposes Company Directors to penalties under the Corporations Act 2001 (Cth), which include monetary fines and jail terms.

${ }^{21}$ While the $\mathrm{CO}_{2}$ average intensity of the Victorian region is $1.215 \mathrm{t} / \mathrm{MWh}$, the fleet average $\mathrm{CO} 2$ intensity of the brown coal fleet is closer to 1.37t/MWh as Simshauser and Doan (2009) demonstrate. Accordingly, the fleet pass-through rate could be thought of as $103 \%$ rather than $116 \%$, again holding all other variables strictly constant.

${ }^{22}$ The apparent price premium of \$4.41/MWh, when applied to the nine-month FY13 energy output of 34,112 GWh results in an apparent 'windfall gain' of $\$ 150$ million. However, the loss of output from FY12 to FY13 (of 39,856 GWh less 34,112 GWh) at the so-called break-even pass-through price of (\$58.17 less $\$ 4.41 / \mathrm{MWh}$ ) results in an even greater offsetting loss of $\$ 309$ million. This result further undermines the Table 4 analysis. 